\title{
Academic Dishonesty of Accounting Students at Higher Learning Institutions
}

\author{
Che Ku Hisam Che Ku Kassim* \\ Noor Emilina Mohd Nasir \\ Suraya Ahmad \\ Universiti Teknologi MARA \\ *Email: cheku521@tganu.uitm.edu.my
}

Doi:10.5901/mjss.2015.v6n4s2p702

\begin{abstract}
Academic dishonesty is a serious educational problem. One of the major consequences of academic dishonesty is the increasing cases of corporate scandals involving accountants. The integrity of accounting programs has been repeatedly questioned since the accounting profession is being entrusted with immense responsibility of preparing and communicating high quality information to a multitude of stakeholders for decision-making purposes. Considering that the accounting students are future business leaders, their academic integrity at the educational level should be given close attention. The main purpose of this paper is to provide a general discussion on an array of academic dishonesty committed by accounting students at higher learning institutions. The discussion also includes factors leading to academic dishonesty such as poor academic policy, the advent of advanced technology and the demographic profile of the students. The penultimate part of the discussion proposes several corrective measures that can be implemented in reducing cases of academic dishonesty. These measures, to be successful, require integrated efforts by many parties concerned. Overall, this paper offers some insights that can be useful in overcoming academic dishonesty from continually being an epidemic on campus.
\end{abstract}

Keywords: academic dishonesty; accounting students; education; ethics; corporate scandals;

\section{Introduction}

The highly publicized corporate malfeasances such as Enron, WorldCom, Parmalat and Global Crossing, to highlight some, have raised concern on the root cause of such unfortunate organizational crises. The concern comes to surface as many of corporate executives who are involved in the fraudulent acts have excellent tertiary education certificates from prestigious institutions. Adler (2002) in arguing on matters leading to corporate scandals asserts that the eroding ethical values may have been the prime influence of the corporate misconducts. Burke et al. (2007, p. 58) further argue that academic dishonesty on campus may be a "contributing factor to the failed ethical conduct of our corporate executives and professional accountants". Brown and Choong (2005) express similar argument and opine that the consequences of academic dishonesty can be devastating. The extant studies documented evidence that students engaging in academic dishonesty on campus are most likely to repeat the behavior when they move into the workplace (Sims, 1993; Granitz \& Loewy, 2007). This, in turn, prompts a question on the reasons that drive students particularly in accounting and business fields to commit academic dishonesty.

In their survey, Brown and Choong (2005) find that the main reason that leads to academic dishonesty among students in both private and public colleges is the intention to attain a high grade. Lupton et al. (2000) argue that intense pressures to obtain good grades for employment purposes have driven low Grade Point Average (GPA) scorers to cheat in tests, quizzes or even in the final exams. Contrary to high-grade scorers, some the low-grade scorers do not strive to obtain better grade and are not prepared before their assessment (Bakar et al., 2010). A similar opinion is expressed by Meng et al. (2014) who contend that students, in general, are likely to be involved in an array of academic dishonesty behaviors just to attain a better grade so that a better job opportunity is available. This seems to suggest that students entering universities are not in the hunt for valuable knowledge but rather to earn a scroll of diploma as a ticket for a better future. Difficulty of material or course is another reason that leads students to be dishonest in their academic studies. Burke et al. (2007) argue that academic dishonesty appears to be more prevalent in rigorous field of studies such as accounting and engineering. The pressure to succeed and advance to the next level of studies often pushes students in these fields of studies to engage in unethical behavior. Peer behavior can also provide normative support for students 
to engage in academic dishonesty. Such behavior can become more serious if the chance of getting caught is low and penalties imposed on such misconduct are not severe enough to be a well-taught lesson.

The aim of the paper is to provide a discussion on an array of dishonest behaviors committed by undergraduate students enrolling in accounting programs. This concept paper reviews the scholarly research in the related area in order to provide a basis for a more detailed discussion on pertinent issues related to academic dishonesty in tertiary educational level. It is hoped that the discussion may shed some light that could assist educators in curbing academic dishonesty from continuously being an epidemic in higher institutions. The remaining parts of the paper are structured as follows. A brief review on the types of academic dishonesty is provided in section 2. Afterwards, section 3 discusses on the factors that lead to academic dishonesty. The factors are ranging from the academic policy, the advent technology to the demographic characteristics of the students. Understanding of these factors is important because students are often regarded as future leaders. Next, a discussion on ways to overcome academic dishonesty is provided. It is worthy to note that the suggested approaches are far from being exhaustive, but they are hoped to give some guidance to the educators in resolving this critical issue in education. A brief conclusion ends the paper.

\section{Literature Review}

\subsection{Types of academic dishonesty}

According to Lambert et al. $(2003$, p.3) academic dishonesty refers to the "fraudulent action or attempt by a writer or writers to use unauthorized or unacceptable means in any academic work". Most often than not, academic dishonesty is committed as a means of getting favorable results in exams (Lupton et al., 2000; Meng et al., 2014). The extant literature often underscores the focus of academically dishonest behavior on cheating activities on examinations, although there are many other forms of dishonesty that occur perhaps the same or even greater frequency than cheating on examinations (Roig \& Caso, 2005). In general, academic dishonesty can be broadly classified into the following categories.

\subsubsection{Cheating in assessment}

Burke et al. (2007) argue that cheating may include any attempt to use or actually using unauthorized sources in order to complete any given assignments or projects. It also, in addition, includes copying the other student's answers during an exam and submitting someone else's work as if it is the student's own effort. According to Jeergal et al. (2015), an attempt to allow or get any unauthorized assistance in academic work can also be constituted under cheating. Besides that, McCabe et al. (2006) also include the act of assisting others in answering questions during test or examination is conducted, and learning in advanced on the tested topics in assessment by asking those who have taken the similar assessment as part of the behavior which can also be considered as cheating. In some higher learning institutions, the misconduct is shown explicitly such as requesting friends to replace them on the examination using their personal identity (Sedmak \& Nastav, 2010). These misconducts have become a common phenomenon in higher learning institutions.

\subsubsection{Plagiarism}

Plagiarism has always been a common problem in courses that require research papers (Burke et al., 2007). The term plagiarism is basically referred to as deliberately misrepresenting the work or ideas as if they were the student's, such as the use of the exact phrases or paraphrases of another without appropriately citing the sources. It has become a culture in universities' environment and inherited from one generation to the other generation of students. Roig and Caso (2005) opine that with the advancement of information technology (IT), the incident of plagiarism has increased dramatically in recent years. One important characteristic of IT is that it provides tools for students to engage in digital plagiarisms by allowing them to use the copy and paste function excessively (Kauffman \& Young, 2015).

\subsubsection{Fraudulent excuse}

Roig and Caso (2005) explain that the use of fraudulent excuse refers to an act of delaying the beginning or completion of academic tasks. In a study by Ferrari and Beck (1998), it is found that the students often use fraudulent excuses in an attempt to gain extra time to complete a given assignment after the due date has elapsed. In Carmichael and Krueger's (2015) study on 319 students, they find that family emergency is the most common reason reported by the students for 
not completing a given assignment. The respondents express higher confidence that the instructor is likely to accept or believe their reason if it is related to family matters.

\subsubsection{Fabrication of work}

This unethical misconduct refers to the unauthorized creation or falsification of any information provided in any coursework such as submitting fake data from a research project, providing fabricated information as truth, and also providing fictitious citations (Burke et al., 2007). On the other hand, McCabe et al. (2006) have provided a list a few behaviors as cheating on written work, which include work together on an individual assignment, claiming other people's work as their work, fabrication of bibliography and providing unauthorized help to someone else.

\subsubsection{Forgery of academic document}

According to Burke et al. (2007) forgery of academic document can be related to an intentionally counterfeiting the signature of a university administrator on academic documents such as registration forms, academic transcripts, or any other related forms. The fudging of academic achievements with the aim of obtaining an edge in the competitive learning environment has come to an extent that academic certificates can be forged through bogus degrees, which are being increasingly offered online by institutions that never exist (Pina, 2010). These unethical activities could bring serious consequences not only to the university but also to the integrity of the education system.

\subsection{Factors contributing to academic dishonesty}

Lupton et al. (2000) lament those students who engage in academic dishonesty present two problematic threats to any educational process. Firstly, it poses a threat to the equity and efficacy of instructional measurement as students' abilities are failed to be evaluated with some degree of accuracy and objectivity. Secondly, it leads to students reducing their level of learning capacity, and consequently, the students become less prepared for advanced study and application of the course material. Burke et al. (2007) argue that there are generally three main factors that could lead to academic dishonesty amongst the students. The first factor is due to poor academic policy. The academic culture is found to have lacks of standards/policies that govern such unethical behavior. Often, the punishments imposed on students who commit acts of academic dishonesty are not severe enough to be a well-taught lesson. Consequently, repeated offences are most likely to occur.

Lack of academic support is another problematic factor that leads to high cases of academic dishonesty. Educators, who are well-aware of their students' cheating behavior, often, refuse to take any action just to avoid dealing with university's bureaucratic process. Such an attitude sends a signal to students, either directly or indirectly, that academic dishonesty is not a serious offence (McCabe et al., 2006). The emergence of highly sophisticated information technology such as the Internet has also, to a certain extent, contributed to the high tendency of students to commit academic dishonesty (Ross, 2005). In seeing this development, Kauffman and Young (2015) assert that academic dishonesty has now evolved to digital cheating and continues to be a plague in higher education settings. The fact that the students are more adept with the latest technology, compared to their educators, creates a wide open opportunity for students to cheat in exams or in doing project assignment. In addition, to use of Internet to sell project papers or essays online also offers an avenue for students to commit academic dishonesty although they may be aware of the fact that such an act is ethically violated.

In addition to Burke et al. (2007), demographic characteristics, as documented by the extant literature, are also found to have some degree of influence on academic dishonesty. Cultural differences, types of academic program enrolled (McCabe et al., 2006), gender and age differences are empirically evident to have some form of influence over the tendency of students to commit various types of academic dishonesty. An experience-based study by Flynn (2003) exhibits evidence that different cultural setting is found to be a significant predictor of academic dishonesty. Asia's students are more tolerance towards academic cheatings compared to American's students. Similarly, Magnus et al. (2002) and Lupton et al. (2000), also present identical findings, where students of European origins tend to have high frequencies of academic dishonesty as opposed to the American counterparts. Moreover, studies also suggest that male students have higher propensity to commit academic dishonesty compared to their opposite gender. In terms of maturity, younger students tend to cheat more often than the more matured students.

Cheating amongst students of business majors (including accounting) is found to be more prevalent compared to other fields of study (McCabe, 1997; Burke et al., 2007). In addition, McCabe et al. (2006) surprisingly find that graduate 
students of business majors tend to commit academic dishonesty more often compared to non-business graduates. Peers influence is also one of the factors that may potentially influence academic dishonesty. In some cases, students are reluctant to engage in academic dishonesty if the environment of the institution encourages whistle blowing. However, not many students are willing to be a whistle blower of an academic dishonesty of their peers. This is because normally the whistle blower will be the target victim of the action, since the culture of "you scratch my back and I will scratch yours" is embedded in the some students' way of life. Thus, this gives a bad sign to the students, since nobody cares to take actions academic dishonesty, it is often viewed as a commonly accepted activity. Bakar et al. (2010) however stress that students are willing to whistle blow if the relevant authority is able to offer some protection or provide proper safety mechanism in order to discourage academic dishonesty.

\subsection{Measures to overcoming academic dishonesty}

Academic dishonesty requires a structured program be designed in handling the incidences of dishonest behavior amongst the students. Dufresne (2004) has emphasized that creating an educational culture with strong sense of integrity requires integrated efforts and dynamic involvement of all participants who are directly connected to the students. In combating the incidence of academic dishonesty, several alternatives measures are proposed.

\subsubsection{Improved academic policy}

Poor academic policy is often prone to high cases of academic misconducts (Burke et al., 2007). Therefore, efforts should be made by universities' top managements to design and issue a clear statement of policy that upholds academic integrity. In the policy, a clear definition of academic policy should be provided together with any penalties that could be faced by the students if the policy is breeched. The most appropriate time to circulate a proper academic policy is during the orientation session. This can ensure students be more aware of the consequences hence, prevent them from engaging in the acts.

\subsubsection{Stern punishments and enforcement}

Burke et al. (2007) suggest that stiffer penalties should be imposed to students for any act of academic dishonesty. This can be seen as a strong message to the students that academic dishonesty is a serious offence that cannot be tolerated. McCabe et al. (2006) have indicated that severe penalties may help to reduce the tendency of students to cheat. However, it is believed that having stern punishments is inadequate if the enforcement is weak. Therefore, in ensuring any initiative towards academic integrity is a success, enforcement of the punishments should be strengthened.

\subsubsection{Reduce the bureaucratic process}

In a study by Jendrek (1989), the majority of academic staff who witnessed students committing academic dishonesty prefers not to report the incident as a lack of support in the administration is observed (Burke et al;, 2007). Moreover, lengthy and complicated bureaucratic process seems to hinder educators to report cases of academic dishonesty. The fear of having to attend countless court proceedings impedes educators to undertake necessary action (McCabe et al., 2006). Therefore, it is suggested that by having the process reduced, if not simplified, educators may be more encouraged to expose cases of academic dishonesty for appropriate scrutinizing.

\subsubsection{The role of educators}

The responsibility of curbing academic dishonesty is perhaps laid on the broad shoulders of the educators due to their direct relationship with the students. McCabe et al. (2006) suggest that faculty members should be proactive and considerable in using many strategies in an effort to avoid creating any cheating opportunities. Flynn (2003, p. 439) lists some strategies that can be employed by educators in minimizing academic misconduct, particularly cheating in examinations which include the use of more proctor for larger classes and the banning of electronic devices. The suggestions made by Flynn (2003) and McCabe et al. (2006), however, may require different set of test questions prepared, high time consumption in checking students' assignments/projects and many other additional duties beyond the boundaries of normal working routines. 


\subsubsection{Ethics and moral education}

According to Brown and Choong (2005), one possible solution to academic dishonesty on the campus is by exposing high level of ethical and moral education to students. They are of the opinion that sufficient coverage on ethics helps business and accounting students to instill professional integrity and develop ethical traits. The calls to recoup the credibility of the accounting profession amidst corporate scandals have been lamented by many prominent scholars. Russell (2003), for example, suggests that education in ethics is seen as the pre-eminent cornerstone to re-instate public confidence in the accounting profession. Trevino and McCabe (1994) address identical argument saying that business education should be constantly be reviewed and kept updated with focus must be emphasized on the application of moral principles in ensuring that education in ethics imparts significant impact on student behaviors.

\section{Concluding Remarks}

Academic dishonesty is a disturbing issue. University's reputation as the producer of high quality human capital can be badly affected, if the crisis is not appropriately tackled. In recent years, the alarming concerns on ethical issues have been witnessed due to many corporate scandals being highlighted in the media. The malpractice of corporate citizens with some shares from professional accountants tarnishes the image of the accounting profession. To rebuild the reputation, the profession needs its members to have strong professional ethics, integrity and accountability. Indeed, education has a pivotal role to play in ensuring just that. Good moral values must be strengthened and persistently enriched by means of formal and informal education processes in ensuring that the accounting profession is seen highly professional with strong sense of integrity and accountability.

\section{References}

Adler, P. S. (2002). Corporate scandals: It's time for reflection in business schools. Academy of Management Executive, 16, 148-149.

Bakar, N. B. A., Ismail, S., \& Mamat, S. (2010). Will graduating year accountancy students cheat in examination? A Malaysian case. International Education Studies, 3, 145-152.

Brown, B. S., \& Choong, P. (2005). An investigation of academic dishonesty among business students at public and private United States universities. International Journal of Management, 22, 210-214.

Burke, J. A., Polimeni, R. S., \& Slavin, N. S. (2007). Academic dishonesty: A crisis on campus. The CPA Journal, 77, 58-65.

Carmichael, A. M., \& Krueger, L. E. (2014). An examination of factors and attitudes that influence reporting fraudulent claims in an academic environment. Active Learning in Higher Education, 15, 173-185.

Dufresne, R. L. (2004). An action learning perspective on effective implementation of academic honor code. Group and Organisation Management, 28, 201-218.

Ferrari, J. F., \& Beck, B. L. (1998). Affective responses before and after fraudulent excuses by academic procrastinators. Education, 118, 529-537.

Flynn, R. T. (2003). Confronting academic dishonesty in the accounting classroom: A cultural experience? Accounting Education, 12, $437-439$.

Granitz, N., \& Loewy, D. (2007). Applying ethical theories: Intrepreting and responding to student plagiarism. Journal of Business Ethics, 7, 293-306.

Jendrek, M. P. (1989). Faculty reactions to academic dishonesty. Journal of College Student Development, 30, 401-406.

Jeergal, P. A., Surekha, R., Sharma, P., Anila, K., Jeergal, V. A., \& Rani, T. (2015). Prevalence, perception and attitude of dental students towards academic dishonesty and ways to overcome cheating behaviours. Journal of Advanced Clinical and Research Insights, 2, 2-6.

Kauffman, Y., \& Young, M. F. (2015). Digital plagiarism: An experimental study of the effect of instructional goals and copy-and-paste affordance. Computer and Education, 83, 44-56.

Lambert, E. G., Hogan, N. L., \& Barton, S. M. (2003). Collegiate academic dishonesty revisited: What have they done, how often have they done it, who does it, and why did they do it. Electronic Journal of Sociology, 7, 1-27.

Lupton, R. A., Chapman, K. J., \& Weiss, J. E. (2000). A cross-national exploration of business students' attitudes, perceptions, and tendencies toward academic dishonesty. Journal of Education for Business, 75, 231-235.

Magnus, J. R., Polterovish, V. M., Danilov, D. L., \& Savvateev, A. V. (2002). Tolerance of cheating: An analysis across countries. Journal of Economic Education, 33, 125-135.

McCabe, D. L. (1997). Classroom cheating among natural science and engineering majors. Science and Engineering Ethics, 3, 433-445.

McCabe, D. L., Butterfield. K. D., \& Trevino, L. K. (2006). Academic dishonesty in graduate business programs: Prevalence, causes, and proposed action. Academy of Management Learning and Education, 5, 294-305.

Meng, C. L., Othman, J., D'Silva, J. L., \& Omar, Z. (2014). Influence of neutralisation attitude in academic dishonesty among undergraduates. International Education Studies, 7, 66-73. 
Pina, A. A. (2010). Online diploma mills: Implications for legitimate distance education. Distance Education, 31, 121-126.

Roig, M., \& Caso, M. (2005). Lying and cheating: Fradulent excuse making, cheating, and plagiarism. The Journal of Psychology, 139, 485-494.

Ross, K. A. (2005). Academic dishonesty and the Internet. Communications of the ACM, 48, 29-31.

Russell, G. (2003). Post-enron malpractice worries on the rise. Accounting Today, 17, 4-6.

Sedmak, S., \& Nastav, B. (2010). Perception of ethical behavior among business studies student. In 11th International Conference on Social Responsibility, Professional Ethics and Management, 24-27. [Online] Available: http://www.fm-kp.si/zalozba/ISBN/978961-266-098-7/papers/MIC9100.pdf

Sims, R. L. (1993). The relationship between academic dishonesty and unethical business practices. Journal of Education for Business, $68,207-211$

Trevino, L. K., \& McCabe, D. (1994). Meta-learning about business ethics: Building honourable business schools communities. Journal of Business Ethics, 13, 405-416. 